\title{
Association Between Helicobacter Pylori Infection and Risk of
}

\section{Nonalcoholic Fatty Liver Disease: an Updated Meta-analysis}

Alessandro Mantovani, MD ${ }^{1}$, Teresa Turino, MD¹, Anna Altomari, MD ${ }^{1}$, Amedeo Lonardo, $\mathrm{MD}^{2}$, Giacomo Zoppini, MD ${ }^{1}$, Luca Valenti, MD ${ }^{3}$, Herbert Tilg, MD ${ }^{4}$, Christopher D. Byrne, MB BCh, $\mathrm{PhD}^{5,6}$, Giovanni Targher, MD ${ }^{1}$

${ }^{1}$ Section of Endocrinology, Diabetes and Metabolism, Department of Medicine, University and Azienda Ospedaliera Universitaria Integrata of Verona, Verona, Italy

${ }^{2}$ Department of Internal Medicine and Metabolic Diseases, Nuovo Ospedale Sant'Agostino Estense di Baggiovara, Modena, Italy

${ }^{3}$ Department of Pathophysiology and Transplantation, University of Milan, and Translational Medicine - Department of Transfusion Medicine and Hematology, Fondazione IRCCS Ca' Granda - Ospedale Maggiore Policlinico Milano, Milan, Italy

${ }^{4}$ Department of Internal Medicine I, Gastroenterology, Hepatology \& Metabolism, Medical University Innsbruck, Innsbruck, Austria

${ }^{5}$ Nutrition and Metabolism, Faculty of Medicine, University of Southampton, Southampton, UK

${ }^{6}$ Southampton National Institute for Health Research Biomedical Research Centre, University Hospital Southampton, Southampton General Hospital, Southampton SO16 6YD, UK

Short Title: Helicobacter pylori infection and NAFLD

Word count: abstract 292; text 3,710 (excluding title page, abstract, references, figure legends, and tables); n. 2 Tables + n. 3 Figures + Online-only Supplementary Material ( $n$. 3 supplementary Tables $+n .4$ supplementary Figures). References $=51$

\author{
Address for correspondence: \\ Prof. Giovanni Targher, MD \\ Section of Endocrinology, Diabetes and Metabolism \\ Department of Medicine \\ University and Azienda Ospedaliera Universitaria Integrata \\ Piazzale Stefani, 1 \\ 37126 Verona, Italy \\ Phone: +39-0458123110 \\ E-mail: giovanni.targher@univr.it
}




\section{ABSTRACT}

Background: Recent studies that have examined the association between Helicobacter pylori infection and risk of nonalcoholic fatty liver disease (NAFLD) have produced conflicting data. We have performed a systematic review and meta-analysis to assess the association between $H$. pylori infection and risk of NAFLD.

Methods: We searched PubMed, Web of Science and Scopus databases using predefined keywords to identify observational studies (published up to November 2018), in which NAFLD was diagnosed by histology, imaging or biochemistry. Data from selected studies were extracted and meta-analysis was performed using random-effects modeling. The statistical heterogeneity among studies $\left(I^{2}\right.$-index $)$, subgroup analyses and the possibility of publication bias were assessed.

Results: Thirteen observational (11 cross-sectional/case-control and 2 longitudinal) studies involving a total of 81,162 middle-aged individuals of predominantly Asian ethnicity $(47.5 \%$ of whom had $H$. pylori infection diagnosed by urea breath test, faecal or serological tests) were included in the final analysis. Meta-analysis of data from crosssectional and case-control studies showed that $H$. pylori infection was associated with increased risk of prevalent NAFLD ( $n=11$ studies; random-effects odds ratio [OR] 1.20, $\left.95 \% \mathrm{Cl} 1.07-1.35 ; l^{2}=59.6 \%\right)$; this risk remained significant in those studies where analysis was fully adjusted for age, sex, smoking, adiposity measures, diabetes or dyslipidemia (random-effects OR 1.19, 95\% Cl 1.07-1.32, $I^{2}=0 \%$ ). Meta-analysis of data from longitudinal studies showed that $H$. pylori infection was also associated with increased NAFLD incidence ( $n=2$ studies; random-effects hazard ratio $1.14,95 \% \mathrm{Cl}$ $\left.1.05-1.23 ; l^{2}=0 \%\right)$. Sensitivity analyses did not alter these findings. Funnel plot did not reveal significant publication bias.

Conclusions: $H$. pylori infection is associated with mildly increased risk of both prevalent and incident NAFLD in middle-aged individuals. More prospective studies, particularly in non-Asian populations, and mechanistic studies are required to better elucidate the link between chronic $H$. pylori infection and NAFLD.

Keywords: Helicobacter pylori; NAFLD; liver fat; meta-analysis 


\section{ABBREVIATION LIST}

BMI, body mass index

$\mathrm{Cl}$, confidence interval

HIS, hepatic steatosis index

H. pylori, Helicobacter pylori

$\mathrm{HR}$, hazard ratio

NAFLD, non-alcoholic fatty liver disease

NAFLD-LFS, NAFLD liver fat score

$\mathrm{NASH}$, non-alcoholic steatohepatitis

NOS, Newcastle-Ottawa Quality Assessment Scale

$\mathrm{OR}$, odds ratio

PRISMA, Preferred Reporting Items for Systematic Reviews and Meta-Analyses 


\section{INTRODUCTION}

Non-alcoholic fatty liver disease (NAFLD) is the leading cause of chronic liver diseases in many parts of the world [1-3]. The global prevalence of NAFLD has been estimated to be nearly $25 \%$ with highest prevalence in the Middle East (31.8\%) and Asia (27.4\%) and lowest in Africa (13.5\%) [2].

Growing evidence suggests that intestinal dysbiosis may be involved in NAFLD pathogenesis, mainly through its effects on innate immune system, gut permeability, intestinal production of short-chain fatty acids, and fermentation of indigestible carbohydrates $[4,5]$. Experimental evidence in animals is also emerging that there is a link between intestinal dysbiosis, evidence of Helicobacter pylori infection and NAFLD pathogenesis [4-7]. H. pylori, a Gram-negative bacterium colonizing the gastric epithelium, is a cofactor in the development of peptic ulcers, gastric cancer and gastric mucosa-associated lymphoid-tissue lymphoma [6]. H. pylori infection represents one of the most frequent gastrointestinal infections in humans [6]. A comprehensive metaanalysis recently showed that $H$. pylori infection varies between different geographic locations, with greater prevalence in developing countries (e.g., $50-65 \%$ in Asia and Latin America) than in developed countries ( 20-35\% in United States and Europe) [8]. Although the evidence is not conclusive, chronic $H$. pylori infection has been also associated with inflammatory bowel diseases, asthma and other allergic manifestations, as well as a variety of other extra-gastrointestinal conditions, including cardiovascular, hematologic and metabolic diseases [9].

In recent years, there has been growing scientific interest in the association between $H$. pylori infection and NAFLD in man $[9,10]$. Indeed, several observational studies have examined the association between $H$. pylori infection and risk of NAFLD in middle-aged individuals who were largely asymptomatic for peptic ulcers or functional dyspepsia, and who did not take $H$. pylori eradication therapy [11-23]. Since the findings of these observational studies have been inconsistent, it remains uncertain whether $H$. pylori infection is associated with increased risk of NAFLD. 
In this systematic review and meta-analysis, we sought to investigate whether, and to what extent, $H$. pylori infection was associated with risk of NAFLD. Given the growing clinical and economic burden of NAFLD worldwide, we believe that clarification of the magnitude of potential adverse effects of $H$. pylori infection on NAFLD risk might also have clinical implications for the prevention and treatment of this common and burdensome disease.

\section{MATERIALS AND METHODS}

\section{Registration of review protocol}

We registered in advance the protocol for this meta-analysis in PROSPERO (International Prospective Register of Systematic Reviews, no. CRD42018117547). This protocol has been performed in accordance with both the Preferred Reporting Items for Systematic Reviews and Meta-Analyses (PRISMA) and the Meta-analysis Of Observational Studies in Epidemiology (MOOSE) guidelines [24].

\section{Data sources and search strategy}

We extensively searched three publication databases (i.e. PubMed, Scopus and Web of Science) for observational studies (published up to November 25, 2018) examining the association between $H$. pylori infection and risk of NAFLD. The search free text terms were "nonalcoholic fatty liver disease" (OR "fatty liver" OR "NAFLD" OR "nonalcoholic steatohepatitis") AND "Helicobacter pylori infection" OR "Helicobacter pylori" OR "Helicobacter infection" OR "H. pylori". Searches were restricted to human studies, whereas no language restrictions were imposed. We also reviewed references from relevant original papers and review articles to identify further eligible studies not covered by the original database searches.

\section{Inclusion and exclusion criteria}

Studies were included if they met the following inclusion criteria: 1) cross-sectional, case-control or longitudinal studies that explored the association between $\mathrm{H}$. pylori 
infection and NAFLD; 2) all studies that reported odds ratios (OR) or hazard ratios (HR) with $95 \%$ confidence intervals $(95 \% \mathrm{Cl})$ values for the exposure/outcome of interest; 3 ) studies in which the diagnosis of NAFLD was based on histology, imaging (mostly ultrasonography) or surrogate markers of NAFLD, such as either the hepatic steatosis index (HIS) or the NAFLD liver fat score (NAFLD-LFS), which include in their equations serum transaminase levels, body mass index (BMI), fasting insulin levels, pre-existing diabetes or metabolic syndrome [25,26], in the absence of significant alcohol intake and other secondary causes of chronic liver disease; and 4) studies in which the presence or previous exposure to $H$. pylori infection was diagnosed using either invasive tests (endoscopic gastric biopsy) or non-invasive tests, such as serological testing (using $\mathrm{H}$. pylori IgG enzyme-linked immunosorbent assays), ${ }^{13} \mathrm{C}$-labeled or ${ }^{14} \mathrm{C}$-labeled urea breath test or faecal antigen test. However, no published studies using endoscopic gastric biopsy were available for the meta-analysis.

Criteria for exclusion were as follows: 1) theses, congress abstracts, case reports, reviews, practice guidelines, commentaries and editorials; 2) studies which did not exclude individuals with significant alcohol intake and other secondary causes of chronic liver disease; 3) studies that did not specifically report any OR or HR and $95 \%$ confidence intervals $(\mathrm{Cl})$ for the outcome measure of interest, and 4) studies performed in pediatric population ( $<18$ years).

Two investigators (AM and GT) independently reviewed the titles and abstracts of all studies identified using the previously described search criteria to identify studies meeting the inclusion criteria. Each study meeting the requirements of the first round inclusion criteria then underwent a full-text independent review by both investigators. Disagreements about the inclusion of studies between investigators were resolved by a third clinical investigator (TT).

\section{Data extraction and quality assessment}

We extracted data on study design, study size, publication year, study country, subjects' characteristics, methods used for the diagnosis of both NAFLD and $H$. pylori infection, outcome of interest, follow-up duration, and list of covariates adjusted in multivariable 
regression analyses. In the case of multiple publications, we included the most up-todate or comprehensive information. We also contacted two corresponding authors of the eligible studies in order to obtain additional information $(13,19)$, but neither of the authors responded to our request.

Two investigators (AM and GT) assessed the risk of bias independently. Any discrepancies were addressed by a re-evaluation of original articles by a third author (TT). Quality assessment was performed according to the Newcastle-Ottawa Quality Assessment Scale (NOS), which is a validated scale for non-randomized studies in meta-analyses [27]. We also used a NOS scale adapted for cross-sectional and casecontrol studies [28]. We judged studies that received a NOS score of at least 8 stars to be at low risk of bias, thus reflecting the highest quality.

\section{Data synthesis and analysis}

The outcome of interest was either the presence or the development of incident cases of NAFLD. The ORs (for cross-sectional/case-control studies) or HRs (for longitudinal studies) and 95\% Cls were considered as the effect size for all the eligible studies. When studies had multiple adjustment models, we extracted only those reflecting the maximum extent of adjustment for risk factors and potential confounders. The adjusted $\mathrm{OR} / \mathrm{HRs}$ of the eligible studies were pooled, and an overall effect size estimate was calculated using a random-effects model.

Visual inspection of the forest plot was employed to examine the possibility of statistical heterogeneity. The statistical heterogeneity among studies was assessed by the chisquare test and the $I^{2}$ statistic, which provides an estimate of the percentage of variability across studies that is due to heterogeneity rather than chance alone [29]. The proportion of heterogeneity accounted for by between study variability was estimated using the $I^{2}$-index and adjudicated to be significant if $I^{2}$ was $>50 \%$. A chi-square test $p$ value $<0.10$ was used to determine statistical significance. 
To examine the sources of heterogeneity among the eligible studies and to test the robustness of the associations, we conducted subgroup analyses by study design, study country, diagnostic methods used for either NAFLD or H. pylori infection, levels of NOS, and degree of adjustment for known risk factors. In addition, we tested for possibly excessive influence of individual studies using a meta-analysis influence test that eliminated each of the included studies one at a time. Finally, we performed univariable meta-regression analyses in order to examine the association of NAFLD with age, sex or BMI.

The possibility of publication bias was evaluated using the funnel plot and the Egger's regression asymmetry test; the trim and fill method was also used for further examining the possibility of publication bias $[27,30]$. STATA® 14.2 (StataCorp, College Station, Tx) was used for all statistical analyses.

\section{RESULTS}

\section{Data search and study characteristics}

Figure 1 lists the results of the literature research and study selection. After excluding duplicates, based on the titles and abstracts of 72 citations, we initially identified 16 potentially relevant studies from publication databases prior to November 25, 2018. After examining the full text of these 16 publications, we further excluded three studies $[31,32,33]$, because of unsatisfactory inclusion criteria or unsatisfactory outcome measures, as specified in the flow diagram.

The main characteristics of the thirteen observational studies included in the metaanalysis are summarized in Table 1. Eleven studies had a cross-sectional $(n=9)$ or case-control $(n=2)$ design, whereas the remaining two studies had a longitudinal design. These studies included a total of 81,162 middle-aged individuals $(47.5 \%$ of whom had H. pylori infection). The overall prevalence of NAFLD in the cross-sectional studies was $30.7 \%$, whereas 3,404 individuals ( $20 \%$ of total) developed incident NAFLD over the follow-up in the longitudinal studies included in the meta-analysis. The diagnosis of 
NAFLD was based on histology ( $n=2$ studies), ultrasonography ( $n=9$ studies) or surrogate markers of NAFLD ( $\mathrm{n}=2$ studies). The diagnosis of $\mathrm{H}$. pylori infection was based non-invasively on serologic testing for Ig $G$ antibodies ( $n=5$ studies), faecal antigen test ( $\mathrm{n}=1$ study), and ${ }^{13} \mathrm{C}$-labeled or ${ }^{14} \mathrm{C}$-labeled urea breath tests ( $\mathrm{n}=7$ studies). Approximately $90 \%$ of the eligible studies were carried out in Asia ( $n=11$ studies from China, Japan, South Korea or Egypt); one population-based study was carried out in the United States and one case-control study was carried out in Greece. Most studies included middle-aged, nonobese individuals (mean age 50.6 years; mean BMI 24.2 $\left.\mathrm{kg} / \mathrm{m}^{2}\right)$, who were predominantly men ( $\left.55 \%\right)$.

As shown in supplementary Table 2, six studies received at least eight stars on the NOS indicating that these studies had a low risk of bias, two studies received seven stars and the remaining studies received six stars or fewer (being at high risk of bias).

\section{H. pylori infection and NAFLD prevalence}

Figure 2 shows the forest plot and pooled estimates of the effect of $H$. pylori infection on the risk of prevalent NAFLD in cross-sectional or case-control studies (involving a total of 63,765 middle-aged individuals).

Overall, $H$. pylori infection was significantly associated with an increased risk of prevalent NAFLD (random-effects OR 1.20, 95\% Cl 1.07-1.35; $I^{2}=59.6 \%$ ). As reported in Table 1, the association between $H$. pylori infection and NAFLD remained significant in those studies where analysis was adjusted for age, sex, smoking, measures of adiposity (BMI or waist circumference), dyslipidemia and diabetes.

As also shown in the forest plot, stratifying for the study design, the significant association between $\mathrm{H}$. pylori infection and risk of NAFLD was consistent both in casecontrol studies (random-effects OR $3.24,95 \% \mathrm{Cl} 1.96-5.36 ; l^{2}=0 \%$ ) and in crosssectional studies (random-effects OR $1.14,95 \% \mathrm{Cl} 1.07-1.22 ; I^{2}=5.5 \%$ ), although it appeared to be stronger in case-control studies. In any case, it is important to underline 
that the stratification by study design abolished the significant heterogeneity we observed in the pooled primary analysis.

As reported in supplementary Figure S1, the Egger's regression test did not show statistically significant asymmetry of the funnel plot $(p=0.34)$, thus suggesting that publication bias was unlikely, although it should be noted that the number of included studies was small. This finding was also confirmed by the trim and fill method (data not shown).

\section{Subgroup analysis and meta-regression}

Table 2 shows the results of subgroup analyses of the cross-sectional and case-control studies (stratified by levels of NOS, degree of covariate adjustment, methods used for diagnosing either H. pylori infection or NAFLD, and study country). Notably, the significant association between $H$. pylori infection and NAFLD was consistent in most subgroups examined (except for studies performed in United States or using the HIS for diagnosing NAFLD).

We performed a sensitivity analysis using the one-study remove (leave-one-out) approach in order to examine the influence of each study on the overall effect size. As shown in supplementary Figure S2, exclusion of each of these studies from the analysis did not show any significant effect on the association between $H$. pylori infection and risk of NAFLD.

Supplementary Figure S3 shows the results of univariable meta-regressions showing the lack of significant effects of age, sex or BMI on the association between $\mathrm{H}$. pylori infection and risk of NAFLD in the cross-sectional and case-control studies.

\section{H. pylori infection and NAFLD incidence}

Figure 3 shows the forest plot and pooled estimates of the effect of $H$. pylori infection on the risk of incident NAFLD in longitudinal studies $(n=2$ studies involving a total of 
17,397 Asian individuals). In these two studies, the diagnosis of $H$. pylori infection was based on serological or faecal tests, whereas the development of incident NAFLD ( $n=3,404$ incident cases), over a median period of nearly 4 years, was detected using either ultrasonography or surrogate markers of NAFLD.

Overall, H. pylori infection was associated with an increased incidence of NAFLD (random-effects HR 1.14, 95\% $\mathrm{Cl} 1.05-1.23 ; I^{2}=0 \%$ ), even after controlling for age, sex, BMI, smoking, physical activity, plasma lipids, diabetes and HOMA-estimated insulin resistance. However, it should be noted that only two Asian studies were available for this analysis.

\section{DISCUSSION}

This meta-analysis includes a total of thirteen observational studies, using mostly ultrasonography or biochemistry-based indexes to diagnose NAFLD with aggregate data on $\sim 81,000$ middle-aged subjects of predominantly Asian ethnicity. Meta-analysis of data from the cross-sectional and case-control studies has shown that $H$. pylori infection was associated with mildly increased risk of prevalent NAFLD ( $n=11$ studies; randomeffects OR $1.20,95 \% \mathrm{Cl} 1.07-1.35 ; l^{2}=59.6 \%$ ). Notably, this risk remained significant in those studies where analysis was fully adjusted for age, sex, smoking, adiposity measures, dyslipidemia and diabetes. Meta-analysis of data from the longitudinal studies has shown that $H$. pylori infection at baseline was also independently associated with a $\sim 15 \%$ increased risk of incident NAFLD over a median follow-up of $\sim 4$ years ( $n=2$ studies; random-effects HR $1.14,95 \% \mathrm{Cl} 1.05-1.23 ; l^{2}=0 \%$ ).

In a previous smaller meta-analysis of six cross-sectional and case-control studies (published up to June 2016 and involving a total of $\sim 38,500$ individuals), Wijarnpreecha et al. reported a significant association between $\mathrm{H}$. pylori infection and increased risk of prevalent NAFLD (random-effects OR 1.21, 95\% Cl 1.07-1.37; $I^{2}=49 \%$ ) [34]. Compared to our meta-analysis, these authors included three identical studies to those included in our meta-analysis $[11,13,15]$, but also three cross-sectional studies with positive results 
[35-37] that were published only as congress abstracts (only one of which has been subsequently published as original paper and then also included in our meta-analysis) [18]. Compared to this prior meta-analysis, we have almost tripled the total sample size by including new observational cross-sectional and, especially, longitudinal studies published in 2017 and 2018, and we have conducted more thorough statistical analysis. During the submission process of our meta-analysis, Zhou et al. published a systematic review and meta-analysis of 15 observational studies (eleven cross-sectional, two casecontrol, and two longitudinal studies) [38]. Compared to our meta-analysis, these authors included almost all studies included in our meta-analysis [11,13-23], with the exception of the study published by Sumida et al. [12], but they also included three cross-sectional studies with positive results $[35,36,39]$ that were published only as congress abstracts. The authors found that the pooled random-effects OR of NAFLD in patients with $H$. pylori infection was $1.19\left(95 \% \mathrm{Cl} 1.11-1.29 ; l^{2}=66 \%\right)$ when compared to patients without $H$. pylori infection. Similar results were also found when subgroup analyses were performed by study design, geographical locations, $H$. pylori testing methods, and degree of covariate adjustment [38].

The present systematic review and meta-analysis did not allow us to systematically examine whether there was a significant, graded relationship between $H$. pylori infection and the histological severity of NAFLD. Currently, in the literature there are only two small case-control studies using liver biopsy for the diagnosis of NAFLD that provided contrasting results [11,12]. Polyzos et al. did not find any significant difference in $H$. pylori infection between patients with NASH and those with simple steatosis [11]. Conversely, Sumida et al. found that NASH patients were more likely to have H. pylori infection than those with simple steatosis [12]. Thus, we believe that further studies are needed to better clarify whether chronic $H$. pylori infection may affect the histological severity of NAFLD.

Collectively, the findings of our meta-analysis support the assertion that $H$. pylori infection is associated with an increased prevalence and incidence of NAFLD in middleaged individuals. However, the overall effect size appears relatively small. We believe that these findings might have some clinical implications for the case finding of $H$. pylori infection in patients with NAFLD; and similarly, the case finding of NAFLD, in patients 
with $H$. pylori infection, especially in Asian individuals where the rates of chronic $H$. pylori infection are very high ( $\sim 50-65 \%)$ and the $H$. pylori strain types are different and more virulent from those usually reported in developed countries [8]. Moreover, it has been also estimated that the prevalence of imaging-defined NAFLD is among the highest in Asian countries (especially in South Korea and China) [2].

The pathophysiological inter-relationships between NAFLD and chronic $H$. pylori infection and are not well understood. However, there is emerging evidence that this pathogen might partly contribute to the development and progression of NAFLD $[7,10,40]$. Some studies have identified Helicobacter species in human liver samples from patients with various chronic liver diseases, including NAFLD $[33,40]$. Furthermore, H. pylori infection may promote NAFLD, possibly through delivery of inflammatory stimuli (e.g., lipopolysaccharide) from Gram -ve microaerophilic $H$. pylori directly into the portal circulation and also via the development of chronic inflammation (e.g., by increasing the levels of interleukin-6, tumor necrosis factor-alpha and other proinflammatory cytokines), enhanced oxidative stress, altered adipocytokine secretion pattern, and systemic insulin resistance $[7,10,40,42]$. Recently, the gut microbiota has been also implicated in NAFLD pathogenesis [4,5]. Cytotoxin-associated gene $A$ antigen (CagA), i.e. the virulence factor of $H$. pylori [6], has been demonstrated to alter the gut microbiota, resulting in the exacerbation of cell proliferation and immune phenotypes. These H. pylori-induced alterations in the microbiota composition and intestinal mucosal barrier may influence the risk of developing NAFLD [4]. Finally, small pilot studies also suggested that $H$. pylori eradication therapy could have some beneficial effects on serum liver enzyme levels and other surrogate markers of NAFLD [23,44-46]. However, further studies are needed to better elucidate the potential benefits of $H$. pylori eradication therapy on NAFLD (before promoting the use of certain antibiotics to prevent or even treat NAFLD).

Our meta-analysis has some important limitations that should be considered. First, the observational design of the studies does not allow establishing a causal relationship between $H$. pylori infection and risk of NAFLD. Second, since the overall quality of some included studies is not consistently high, and some of these studies have reported incomplete adjustments for known risk factors of NAFLD (e.g., waist circumference and 
insulin resistance), the possibility of residual confounding by unmeasured factors cannot be ruled out. Importantly, in none of the eligible studies the association between $H$. pylori infection and NAFLD was adjusted for diet composition, lifestyle, and socioeconomic factors. Third, although we used a random-effects model, some results of our meta-analysis require careful interpretation (given the medium-high heterogeneity observed in the pooled primary analysis of cross-sectional/case-control studies $\left.\left[I^{2}=59.6 \%\right]\right)$. In contrast, no heterogeneity was observed in the pooled primary analysis of longitudinal studies $\left(I^{2}=0 \%\right)$. However, when we examined the possible sources of statistical heterogeneity using subgroup analyses, we found that the observed mediumhigh heterogeneity most likely reflected differences in the study design of the studies (case-control vs. cross-sectional). Fourth, most studies originate from Asian countries (11 out of 13 studies), where large populations undergo regular health check-up programs, including liver ultrasonography and non-invasive tests for $\mathrm{H}$. pylori infection. As Asian and non-Asian populations have different genetic/cultural backgrounds, dietary habits and body fat distributions, as well as different $H$. pylori infection rates and strains, further studies should be conducted in non-Asian populations. Fifth, the studies included in the meta-analysis used either urea breath test or faecal antigen test (i.e., the two most accurate diagnostic methods in clinical practice, which have a specificity and sensitivity of $\sim 95 \%$ ) or serological testing for IgG antibodies (that is the least accurate and cannot distinguish current from past infection) for diagnosing $\mathrm{H}$. pylori infection [6]. Unfortunately, none of the studies confirmed the diagnosis by means of endoscopic gastric biopsy. Finally, another possible limitation of this meta-analysis is that only two case-control studies used liver biopsy (i.e. the reference method for diagnosing and staging NAFLD), whereas most studies used liver ultrasonography [47-49].

Despite these limitations, our meta-analysis has several important strengths. The large number of individuals with $H$. pylori infection and NAFLD has provided high statistical power to assess the magnitude of the relationship between these two common conditions. Finally, although a selective reporting bias of eligible studies could be not definitely excluded (because we did not include 'grey' literature in the meta-analysis, i.e., unpublished studies and studies published outside widely available journals), we think our comprehensive search has made it unlikely that any published reports were missed, whilst visual inspection of the funnel plot and the Egger's regression test did not reveal 
any significant publication bias. There is debate in the literature about the inclusion or exclusion of 'grey' literature in a meta-analysis. Although it is plausible to hypothesize that meta-analyses not including unpublished or grey literature study results are likely to overestimate the pooled effect estimates (especially in those meta-analyses that examined the effectiveness of intervention of randomized controlled trials), current research shows that this is only the case in a minority of meta-analyses $(50,51)$. That said, as reported in supplementary Figure S4, we did not observe any difference in the pooled primary analysis of cross-sectional/case-control studies ( $\mathrm{n}=14$ studies; randomeffects OR $1.21,95 \% \mathrm{Cl} 1.11-1.33 ; I^{2}=57.5 \%$ ), even when we included in our metaanalysis three cross-sectional studies (included in the two aforementioned metaanalyses $[34,38])$ that were published only as congress abstracts $[35,36,39]$.

In conclusion, the results of this updated systematic review and meta-analysis of observational studies suggest that $H$. pylori infection was associated with mildly increased risk of both prevalent and incident NAFLD in middle-aged individuals. However, it is important to note that the observational design of the eligible studies does not allow for establishing a causal association between $\mathrm{H}$. pylori infection and NAFLD. Further studies, particularly in non-Asian individuals, are certainly needed to further validate these findings.

Conflicts of Interest: All authors declare no conflicts of interest.

Authors Contributions: study concept and design: GT; acquisition of data: AM, TT, AA, GT; statistical analysis of data: AM, GT; analysis and interpretation of data: AM, TT, AA, AL, GZ, LV, HT, CDB and GT; drafting of the manuscript: AM, GT; critical revision of the manuscript for important intellectual content: AL, GZ, LV, HT and CDB. GT is the guarantor who takes full responsibility for the work as a whole, including the study design, access to data, and the decision to submit and publish the manuscript. All authors have approved the submitted manuscript. 
Funding: GT is supported in part by grants from the University School of Medicine of Verona, Verona, Italy. CDB is supported in part by grants from the Southampton National Institute for Health Research Biomedical Research Centre.

\section{REFERENCES}

1. Lonardo A, Bellentani S, Argo CK, Ballestri S, Byrne CD, Caldwell SH, et al. Epidemiological modifiers of non-alcoholic fatty liver disease: focus on high-risk groups. Dig Liver Dis. 2015; 7:997-1006.

2. Younossi Z, Anstee QM, Marietti M, Hardy T, Henry L, Eslam M, George J, Bugianesi E. Global burden of NAFLD and NASH: trends, predictions, risk factors and prevention. Nat Rev Gastroenterol Hepatol. 2018;15:11-20.

3. Fazel Y, Koenig AB, Sayiner M, Goodman ZD, Younossi ZM. Epidemiology and natural history of non-alcoholic fatty liver disease. Metabolism. 2016;65:10171025.

4. Moschen AR, Kaser S, Tilg H. Non-alcoholic steatohepatitis: a microbiota-driven disease. Trends Endocrinol Metab. 2013;24:537-545.

5. Tripathi A, Debelius J, Brenner DA, Karin M, Loomba R, Schnabl B, et al. The gut-liver axis and the intersection with the microbiome. Nat Rev Gastroenterol Hepatol. 2018;15:397-411.

6. McColl KE. Clinical practice. Helicobacter pylori infection. N Engl J Med. 2010;362:1597-1604.

7. Castaño-Rodríguez N, Mitchell HM, Kaakoush NO. NAFLD, Helicobacter species and the intestinal microbiome. Best Pract Res Clin Gastroenterol. 2017;31:657-668.

8. Zamani M, Ebrahimtabar F, Zamani V, Miller WH, Alizadeh-Navaei R, ShokriShirvani J, et al Systematic review with meta-analysis: the worldwide prevalence of Helicobacter pylori infection. Aliment Pharmacol Ther. 2018:47:868-876.

9. de Korwin JD, laniro G, Gibiino G, Gasbarrini A. Helicobacter pylori infection and extragastric diseases in 2017. Helicobacter. 2017;22 suppl 1.

10. Cheng DD, He C, Ai HH, Huang Y, Lu NH. The possible role of Helicobacter pylori infection in non-alcoholic fatty liver disease. Front Microbiol. 2017;8:743.

11. Polyzos SA, Kountouras J, Papatheodorou A, Patsiaoura K, Katsiki E, Zafeiriadou $\mathrm{E}$, et al. Helicobacter pylori infection in patients with nonalcoholic fatty liver disease. Metabolism. 2013;62:121-126.

12. Sumida Y, Kanemasa K, Imai S, Mori K, Tanaka S, Shimokobe H, et al. Helicobacter pylori infection might have a potential role in hepatocyte ballooning in nonalcoholic fatty liver disease. J Gastroenterol. 2015;50:996-1004.

13. Okushin K, Takahashi Y, Yamamichi N, Shimamoto T, Enooku K, Fujinaga H, et al. Helicobacter pylori infection is not associated with fatty liver disease including non-alcoholic fatty liver disease: a large-scale cross-sectional study in Japan. BMC Gastroenterol. 2015;15:25. 
14. Zhang C, Guo L, Qin Y, Li G. Correlation between Helicobacter pylori infection and polymorphism of adiponectin gene promoter $-11391 \mathrm{G} / \mathrm{A}$, superoxide dismutase gene in nonalcoholic fatty liver disease. Zhong Nan Da Xue Xue Bao Yi Xue Ban. 2016;41:359-366.

15. Baeg MK, Yoon SK, Ko SH, Noh YS, Lee IS, Choi MG. Helicobacter pylori infection is not associated with nonalcoholic fatty liver disease. World J Gastroenterol. 2016;22:2592-2600.

16. Chen CX, Mao YS, Foster P, Zhu ZW, Du J, Guo CY. Possible association between Helicobacter pylori infection and nonalcoholic fatty liver disease. Appl Physiol Nutr Metab. 2017;42:295-301.

17. Cai O, Huang Z, Li M, Zhang C, Xi F, Tan S. Association between Helicobacter pylori infection and nonalcoholic fatty liver disease: a single-center clinical study. Gastroenterol Res Pract. 2018;2018:8040262.

18. Kang SJ, Kim HJ, Kim D, Ahmed A. Association between cagA negative Helicobacter pylori status and nonalcoholic fatty liver disease among adults in the United States. PLoS One. 2018;13:e0202325.

19. Lu LJ, Hao NB, Liu JJ, Li X, Wang RL. Correlation between Helicobacter pylori infection and metabolic abnormality in general population: a cross-sectional study. Gastroenterol Res Pract. 2018;2018:7410801.

20. Fan N, Peng L, Xia Z, Zhang L, Wang Y, Peng Y. Helicobacter pylori infection is not associated with non-alcoholic fatty liver disease: a cross-sectional study in china. Front Microbiol. 2018;9:73.

21. Yu YY, Cai JT, Song ZY, Tong YL, Wang JH. The associations among Helicobacter pylori infection, white blood cell count and nonalcoholic fatty liver disease in a large Chinese population. Medicine (Baltimore). 2018;97:e13271.

22. Kim TJ, Sinn DH, Min YW, Son HJ, Kim JJ, Chang Y, et al. A cohort study on Helicobacter pylori infection associated with nonalcoholic fatty liver disease. J Gastroenterol. 2017;52:1201-1210.

23. Abdel-Razik A, Mousa N, Shabana W, Refaey M, Elhelaly R, Elzehery R, et al. Helicobacter pylori and non-alcoholic fatty liver disease: A new enigma? Helicobacter. 2018;23:e12537.

24. Stroup DF, Berlin JA, Morton SC, Olkin I, Williamson GD, Rennie D, et al. Metaanalysis of observational studies in epidemiology: a proposal for reporting. Meta-analysis Of Observational Studies in Epidemiology (MOOSE) group. JAMA. 2000;283:2008-2012.

25. Lee JH, Kim D, Kim HJ, Lee CH, Yang JI, Kim W, et al. Hepatic steatosis index: a simple screening tool reflecting nonalcoholic fatty liver disease. Dig Liver Dis. 2010;42:503-508.

26. Kotronen A, Peltonen M, Hakkarainen A, Sevastianova K, Bergholm R, Johansson LM, et al. Prediction of non-alcoholic fatty liver disease and liver fat using metabolic and genetic factors. Gastroenterology. 2009;137:865-872.

27. Higgins JPT, Green S, Editors. Cochrane handbook for systematic reviews of interventions version 5.1.0. The Cochrane Collaboration; 2011 [updated March 2011]. Available from www.cochrane-handbook.org/accessed date: 30 September 2018.

28. Modesti PA, Reboldi G, Cappuccio FP, Agyemang C, Remuzzi G, Rapi S, et al; ESH Working Group on CV Risk in Low Resource Settings. Panethnic differences in blood pressure in Europe: a systematic review and meta-analysis. PLoS One. 2016;11:e0147601. 
29. Higgins JP, Thompson SG. Quantifying heterogeneity in a meta-analysis. Stat Med. 2002;21:1539-1558.

30. Egger M, Smith GD, Phillips AN. Meta-analysis: principles and procedures. BMJ. 1997;315:1533-1537.

31. Doğan Z, Filik L, Ergül B, Sarikaya M, Akbal E. Association between Helicobacter pylori and liver-to-spleen ratio: a randomized-controlled singleblind study. Eur J Gastroenterol Hepatol. 2013;25:107-110.

32. Lecube A, Valladares S, López-Cano C, Gutiérrez L, Ciudin A, Fort JM, et al. The role of morbid obesity in the promotion of metabolic disruptions and nonalcoholic steatohepatitis by Helicobacter Pylori. PLoS One. 2016;11:e0166741.

33. Pirouz T, Zounubi L, Keivani $H$, Rakhshani N, Hormazdi M. Detection of helicobacter pylori in paraffin-embedded specimens from patients with chronic liver diseases, using the amplification method. Dig Dis Sci. 2009;54:1456-1459.

34. Wijarnpreecha K, Thongprayoon C, Panjawatanan P, Manatsathit W, Jaruvongvanich $V$, Ungprasert $P$. Helicobacter pylori and risk of nonalcoholic fatty liver disease: a systematic review and meta-analysis. J Clin Gastroenterol. 2018;52:386-391.

35. Shen ZQY, Lu Y, Yu C, Yu C, Li Y. Association between Helicobacter pylori infection diagnosed by serological status and nonalcoholic fatty liver disease: a cross-sectional study. United Eur Gastroenterol J. 2013;1:A99.

36. Tang DMCD, Chou JY, Ho N, Voellinger MT, Simcox TL, Auh S, et al. Helicobacter pylori infection is strongly associated with metabolic syndrome, and almost meets significance with non-alcoholic fatty liver disease, in a United States Hispanic population. Gastroenterology. 2016;4:S299.

37. Kang SKD KJ, Cho S. Association between Helicobacter pylori and nonalcoholic fatty liver disease in the general population. Helicobacter. 2013;18(suppl 1):114.

38. Zhou BG, Yang HJ, Xu W, Wang K, Guo P, Ai YW. Association between Helicobacter pylori infection and nonalcoholic fatty liver disease: a systematic review and meta-analysis of observational studies. Helicobacter. 2019:e12576. doi: 10.1111/hel.12576 [Epub ahead of print].

39. Kumar R, Dixit VK, Shukla SK, Ghosh J, Ranjan A. The association of Helicobacter pylori infection in non alcoholic fatty liver disease patients. Indian J Gastroenterol. 2017;36:A33.

40. Okushin K, Tsutsumi T, Ikeuchi K, Kado A, Enooku K, Fujinaga H, et al. Helicobacter pylori infection and liver diseases: epidemiology and insights into pathogenesis. World J Gastroenterol. 2018;24:3617-3625.

41. Nilsson HO, Taneera J, Castedal M, Glatz E, Olsson R, Wadstrom T. Identification of Helicobacter pylori, other Helicobacter species by PCR, hybridization, and partial DNA sequencing in human liver samples from patients with primary sclerosing cholangitis or primary biliary cirrhosis. J Clin Microbiol. 2000;38:1072-1076.

42. Polyzos SA, Kountouras J, Zavos C, Deretzi G. The association between Helicobacter pylori infection and insulin resistance: a systematic review. Helicobacter. 2011;16:79-88.

43. Li JZ, Li JY, Wu TF, Xu JH, Huang CZ, Cheng D, et al. Helicobacter pylori infection is associated with type 2 diabetes, not type 1 diabetes: an updated meta-analysis. Gastroenterol Res Pract. 2017;2017:5715403. 
44. Polyzos SA, Nikolopoulos $P$, Stogianni A, Romiopoulos I, Katsinelos $P$, Kountouras J. Effect of Helicobacter pylori eradication on hepatic steatosis, NAFLD fibrosis score and HSENSI in patients with nonalcoholic steatohepatitis: a MR imaging-based pilot open-label study. Arq Gastroenterol. 2014;51:261268.

45. Ando T, Ishikawa T, Takagi T, Imamoto E, Kishimoto E, Okajima A, et al. Impact of Helicobacter pylori eradication on circulating adiponectin in humans. Helicobacter. 2013;18:158-164.

46. Jamali R, Mofid A, Vahedi H, Farzaneh R, Dowlatshahi S. The Effect of Helicobacter pylori eradication on liver fat content in subjects with non-alcoholic fatty liver disease: a randomized open-label clinical trial. Hepat Mon. 2013;13:e14679.

47. Italian Association for the Study of the Liver (AISF). AISF position paper on nonalcoholic fatty liver disease (NAFLD): updates and future directions. Dig Liver Dis. 2017;49:471-483.

48. Chalasani N, Younossi Z, Lavine JE, Charlton M, Cusi K, Rinella M, et al. The diagnosis and management of nonalcoholic fatty liver disease: practice guidance from the American Association for the Study of Liver Diseases. Hepatology. 2018;67:328-357.

49. Byrne CD, Patel J, Scorletti E, Targher G. Tests for diagnosing and monitoring non-alcoholic fatty liver disease in adults. BMJ. 2018;362:k2734.

50. Conn VS, Valentine JC, Cooper HM, Rantz MJ. Grey literature in metaanalyses. Nurs Res. 2003;52:256-261.

51. Schmucker CM, Blümle A, Schell LK, Schwarzer G, Oeller P, Cabrera L, et al; OPEN consortium. Systematic review finds that study data not published in full text articles have unclear impact on meta-analyses results in medical research. PLoS One. 2017;12:e0176210. 


\section{FIGURE LEGENDS}

Figure 1. The PRISMA flow diagram of the meta-analysis.

Figure 2. Forest plot and pooled estimates of the effect of $H$. pylori infection (diagnosed non-invasively by serological test or urea breath test) on the risk of prevalent NAFLD in cross-sectional or case-control studies $(n=11)$. Legend for the forest plot figure: the continued line represents the null line indicating no difference between two groups; the dotted line represents the overall point effect estimate; the empty diamond represents the overall point effect estimate and $95 \%$ confidence intervals; the full diamond represents the point effect estimate for each study with $95 \%$ confidence intervals represented as length of the lines; the square symbols represent the weight of the study. Abbreviations: HPI, Helicobacter pylori infection; I-squared, $I^{2}$ statistic.

Figure 3. Forest plot and pooled estimates of the effect of $H$. pylori infection (diagnosed non-invasively by serological or faecal tests) on the risk of incident NAFLD in longitudinal studies $(n=2)$. Legend for the forest plot figure: the continued line represents the null line indicating no difference between two groups; the dotted line represents the overall point effect estimate; the empty diamond represents the overall point effect estimate and $95 \%$ confidence intervals; the full diamond represents the point effect estimate for each study with $95 \%$ confidence intervals represented as length of the lines; the square symbols represent the weight of the study. Abbreviations: HPI, Helicobacter pylori infection; I-squared, $I^{2}$ statistic.

Figure S1. Funnel plot of standard error by log-odds ratio for the risk of NAFLD (for cross-sectional studies, $n=9$ ). Egger's regression test: $p$-value $=0.34$.

Figure S2. Meta-analysis estimates, given named study is omitted. The effect size was expressed as random-effects OR and $95 \%$ confidence interval for eligible crosssectional and case-control studies $(n=11)$. 
Figure S3. Univariable linear meta-regression analyses. A meta-analysis of the association of age, sex or body mass index with the risk of prevalent NAFLD. Only cross-sectional and case-control studies were included in these meta-regression analyses $(n=11)$.

Figure S4. Forest plot and pooled estimates of the effect of $H$. pylori infection on the risk of prevalent NAFLD in cross-sectional or case-control studies $(n=14)$. In this analysis, we also included three cross-sectional studies that have been published only as congress abstracts $[35,36,39]$. 
Table 1. Principal observational, cross-sectional, case-control or longitudinal studies examining the association between presence of $H$. pylori infection and risk of NAFLD (ordered by publication year).

\begin{tabular}{|c|c|c|c|c|c|}
\hline Authors, Year (Ref.) & $\begin{array}{l}\text { Study Design, Sample Size, } \\
\text { and Population } \\
\text { Characteristics }\end{array}$ & $\begin{array}{l}\text { Diagnostic Methods } \\
\text { for NAFLD, and } \\
\text { Prevalence of NAFLD }\end{array}$ & $\begin{array}{l}\text { Diagnostic Methods for } H \text {. } \\
\text { pylori infection, and } \\
\text { Prevalence of } H \text {. pylori } \\
\text { infection }\end{array}$ & Covariate Adjustment(s) & Main Results \\
\hline \multicolumn{6}{|l|}{$\begin{array}{l}\text { Cross-sectional or } \\
\text { case-control studies } \\
(\mathrm{n}=11)\end{array}$} \\
\hline $\begin{array}{l}\text { Polyzos SA et al. } \\
2013(11)\end{array}$ & $\begin{array}{l}\text { Case-control study: } 28 \text { Greek } \\
\text { adult patients with biopsy- } \\
\text { proven NAFLD ( } 15 \text { with simple } \\
\text { steatosis, } 13 \text { with NASH) and } \\
25 \text { age-, sex- and BMI- } \\
\text { matched healthy controls. } 12 \\
\text { men; mean age } 54 \text { years; } \\
\text { mean BMl } 31 \mathrm{~kg} / \mathrm{m}^{2}\end{array}$ & $\begin{array}{l}\text { Biopsy; } 52.8 \%(n=28) \\
\text { had NAFLD }\end{array}$ & $\begin{array}{l}\text { Antibodies (IgG } \\
\text { enzyme-linked } \\
\text { immunosorbent assay) } \\
\text { and/or }{ }^{13} \mathrm{C} \text { urea breath test; } \\
37(69.8 \%) \text { seropositive } \\
\text { cases }\end{array}$ & Age, sex, BMl & $\begin{array}{l}\text { H. pylori infection was } \\
\text { significantly associated with } \\
\text { NAFLD (adjusted OR } 3.61 \text {, } \\
95 \% \mathrm{Cl} 1.04-12.6 \text { ). No } \\
\text { significant difference was } \\
\text { found in } H \text {. pylori infection } \\
\text { between patients with NASH } \\
\text { and those with simple } \\
\text { steatosis }\end{array}$ \\
\hline $\begin{array}{l}\text { Sumida Y et al. } 2013 \\
\text { (12) }\end{array}$ & $\begin{array}{l}\text { Cross-sectional study: } 130 \text { (65 } \\
\text { men) Japanese adult patients } \\
\text { with biopsy-proven NAFLD ( } 43 \\
\text { with simple steatosis and } 87 \\
\text { with NASH). Mean age } 55.2 \\
\text { years; mean BMl } 27.5 \mathrm{~kg} / \mathrm{m}^{2}\end{array}$ & $\begin{array}{l}\text { Biopsy; } 100 \%(n=130) \\
\text { had NAFLD }\end{array}$ & $\begin{array}{l}\text { Antibodies (IgG } \\
\text { enzyme-linked } \\
\text { immunosorbent assay); } 52 \\
(40 \%) \text { seropositive cases }\end{array}$ & $\begin{array}{l}\text { Age, sex, obesity, } \\
\text { dyslipidemia, } \\
\text { hypertension, diabetes }\end{array}$ & $\begin{array}{l}\text { H. pylori infection was } \\
\text { significantly associated with } \\
\text { NASH (adjusted OR } 2.91 \text {, } \\
95 \% \mathrm{Cl} 1.11-7.6 \text { ) }\end{array}$ \\
\hline $\begin{array}{l}\text { Okushin K et al. } 2015 \\
\text { (13) }\end{array}$ & $\begin{array}{l}\text { Cross-sectional study: } 5,289 \\
(1,816 \text { men) asymptomatic } \\
\text { Japanese alcohol-free adult } \\
\text { individuals without other } \\
\text { known causes of chronic liver } \\
\text { disease. Mean age } 49 \text { years; } \\
\text { mean BMl } 23 \mathrm{~kg} / \mathrm{m}^{2}\end{array}$ & $\begin{array}{l}\text { Ultrasonography; } \\
34.1 \%(n=1,802) \text { had } \\
\text { NAFLD }\end{array}$ & $\begin{array}{l}\text { Antibodies (IgG } \\
\text { enzyme-linked } \\
\text { immunosorbent assay); } \\
1,449(27.4 \%) \text { seropositive } \\
\text { cases }\end{array}$ & None & $\begin{array}{l}\text { H. pylori infection was not } \\
\text { significantly associated with } \\
\text { NAFLD in the whole sample } \\
\text { (unadjusted OR } 1.13,95 \% \mathrm{Cl} \\
0.99-1.28 \text { ); this association } \\
\text { was statistically significant in } \\
\text { women (unadjusted OR } 1.24 \text {, } \\
95 \% \mathrm{Cl} 1.05-1.46 \text { ) but not in } \\
\text { men (unadjusted OR } 1.02 \text {, } \\
95 \% \mathrm{Cl} 0.83-1.26 \text { ) }\end{array}$ \\
\hline $\begin{array}{l}\text { Zhang C et al. } 2016 \\
\text { (14) }\end{array}$ & $\begin{array}{l}\text { Case-control hospital-based } \\
\text { study: } 600 \text { Chinese adult } \\
\text { patients with NAFLD and } 600 \\
\text { age-, sex-, race- and } \\
\text { birthplace-matched healthy } \\
\text { controls }\end{array}$ & $\begin{array}{l}\text { Ultrasonography; } 50 \% \\
(n=600) \text { had NAFLD }\end{array}$ & $\begin{array}{l}{ }^{14} \mathrm{C} \text { urea breath test; } \\
444(37 \%) \text { positive cases }\end{array}$ & Age, sex, race, birthplace & $\begin{array}{l}\text { H. pylori infection was } \\
\text { significantly associated with } \\
\text { NAFLD (adjusted OR } 3.17 \text {, } \\
95 \% \mathrm{Cl} 1.91-5.74 \text { ) }\end{array}$ \\
\hline $\begin{array}{l}\text { Baeg MK et al. } 2016 \\
\text { (15) }\end{array}$ & $\begin{array}{l}\text { Cross-sectional study: } 3,663 \\
(2,141 \text { men) asymptomatic } \\
\text { South Korean adult individuals }\end{array}$ & $\begin{array}{l}\text { Hepatic steatosis index } \\
\text { (HIS) }>36(25.8 \% \text { had } \\
\text { NAFLD; } n=945) \text { or }\end{array}$ & $\begin{array}{l}{ }^{13} \mathrm{C} \text { urea breath test; } 1,636 \\
(44.7 \%) \text { positive cases }\end{array}$ & $\begin{array}{l}\text { Age, sex, smoking, } \\
\text { plasma hs-CRP }\end{array}$ & $\begin{array}{l}\text { H. pylori infection was not } \\
\text { associated with NAFLD as } \\
\text { estimated by HIS (adjusted }\end{array}$ \\
\hline
\end{tabular}




\begin{tabular}{|c|c|c|c|c|c|}
\hline & $\begin{array}{l}\text { after excluding those with } \\
\text { known causes of chronic liver } \\
\text { diseases. Median age } 53 \\
\text { years, median BMI } 23.6 \mathrm{~kg} / \mathrm{m}^{2}\end{array}$ & $\begin{array}{l}\text { NAFLD liver fat score } \\
\text { (NAFLD-LFS) }>-0.64 \\
(23.3 \% \text { had NAFLD) }\end{array}$ & & & $\begin{array}{l}\text { OR } 1.13,95 \% \mathrm{Cl} 0.97-1.31) \\
\text { Similar results were found } \\
\text { using the NAFLD-LFS }\end{array}$ \\
\hline $\begin{array}{l}\text { Chen CX et al. } 2017 \\
(16)\end{array}$ & $\begin{array}{l}\text { Cross-sectional study: } 2,263 \\
(1,424 \text { men) elderly Chinese } \\
\text { individuals after excluding } \\
\text { those with major causes of } \\
\text { chronic liver diseases. Mean } \\
\text { age } 69 \text { years }\end{array}$ & $\begin{array}{l}\text { Ultrasonography; } \\
26.6 \%(n=603) \text { had } \\
\text { NAFLD }\end{array}$ & $\begin{array}{l}{ }^{13} \mathrm{C} \text { urea breath test; } 1,036 \\
(45.8 \%) \mathrm{HPI} \text { positive cases }\end{array}$ & $\begin{array}{l}\text { Age, sex, BMI, waist } \\
\text { circumference, } \\
\text { hemoglobin A1c, } \\
\text { triglycerides, uric acid, } \\
\text { AST, ALT, GGT levels }\end{array}$ & $\begin{array}{l}\text { H. pylori infection was } \\
\text { significantly associated with } \\
\text { NAFLD (adjusted OR } 1.39 \text {, } \\
95 \% \mathrm{Cl} 1.05-1.73 \text { ) }\end{array}$ \\
\hline Cai O et al. 2018 (17) & $\begin{array}{l}\text { Cross-sectional study: } 2,051 \\
\text { ( } 714 \text { male) asymptomatic } \\
\text { Chinese adult individuals after } \\
\text { excluding those with major } \\
\text { causes of chronic liver } \\
\text { diseases. Mean age } 38.1 \\
\text { years, mean BMI } 23.5 \mathrm{~kg} / \mathrm{m}^{2}\end{array}$ & $\begin{array}{l}\text { Ultrasonography; } \\
21.1 \%(n=433) \text { had } \\
\text { NAFLD }\end{array}$ & $\begin{array}{l}{ }^{13} \mathrm{C} \text { urea breath test; } 645 \\
(31.4 \%) \text { positive cases }\end{array}$ & $\begin{array}{l}\text { Sex, BMI, fasting glucose } \\
\text { levels, triglycerides, HDL- } \\
\text { cholesterol }\end{array}$ & $\begin{array}{l}\text { H. pylori infection was not } \\
\text { associated with NAFLD } \\
\text { (adjusted OR 0.94, 95\%Cl } \\
0.70-1.27 \text { ) }\end{array}$ \\
\hline $\begin{array}{l}\text { Kang SJ et al. } 2018 \\
(18)\end{array}$ & $\begin{array}{l}\text { Cross-sectional study } \\
\text { (NHANES 1988-94): } 5,404 \\
(2,540 \text { men) United States } \\
\text { adult individuals after } \\
\text { excluding those with known } \\
\text { causes of chronic liver } \\
\text { diseases. Mean age } 44 \text { years, } \\
\text { mean BMI } 27 \mathrm{~kg} / \mathrm{m}^{2}\end{array}$ & $\begin{array}{l}\text { Ultrasonography; } \\
31.9 \%(n=1,633) \text { had } \\
\text { NAFLD }\end{array}$ & $\begin{array}{l}\text { Antibodies (IgG } \\
\text { enzyme-linked } \\
\text { immunosorbent assay plus } \\
\text { anti-cagA IgG); } 2,655 \\
\text { ( } 49.1 \% \text { ) seropositive cases }\end{array}$ & $\begin{array}{l}\text { Age, sex, race/ethnicity, } \\
\text { waist circumference, } \\
\text { income, diabetes, } \\
\text { hypertension, smoking, } \\
\text { alcohol consumption, } \\
\text { caffeine consumption, } \\
\text { total cholesterol, HDL- } \\
\text { cholesterol, transferrin } \\
\text { saturation }\end{array}$ & $\begin{array}{l}\text { H. pylori infection was not } \\
\text { associated with NAFLD } \\
\text { (adjusted OR } 1.17,95 \% \mathrm{Cl} \\
0.95-1.43 \text { ). However, in } \\
\text { terms of cagA protein status } \\
\text { stratification, while cagA } \\
\text { positive } H \text {. pylori group did } \\
\text { not associate with NAFLD } \\
\text { (adjusted OR } 1.05,95 \% \mathrm{Cl} \\
0.81-1.37 \text { ), cagA negative } H \text {. } \\
\text { pylori group was significantly } \\
\text { associated with NAFLD } \\
\text { (adjusted OR } 1.30,95 \% \mathrm{Cl} \\
\text { 1.01-1.67) }\end{array}$ \\
\hline Lu LJ et al. 2018 (19) & $\begin{array}{l}\text { Cross-sectional study: } 1,867 \\
\text { (1,474 men) asymptomatic } \\
\text { Chinese adult individuals after } \\
\text { excluding those with known } \\
\text { causes of chronic liver } \\
\text { diseases and those who had } \\
\text { received HPI eradication } \\
\text { therapy. Mean age } 54 \text { years }\end{array}$ & $\begin{array}{l}\text { Ultrasonography; } \\
31.9 \%(n=596) \text { had } \\
\text { NAFLD }\end{array}$ & $\begin{array}{l}{ }^{13} \mathrm{C} \text { urea breath test; } 589 \\
(31.5 \%) \text { positive cases }\end{array}$ & None & $\begin{array}{l}\text { H. pylori infection was not } \\
\text { associated with NAFLD } \\
\text { (unadjusted OR } 1.13,95 \% \mathrm{Cl} \\
0.92-1.39 \text { ) }\end{array}$ \\
\hline Fan $N$ et al. 2018 (20) & $\begin{array}{l}\text { Cross-sectional study: } 21,456 \\
\text { (14,389 men) Chinese adult } \\
\text { individuals after excluding } \\
\text { those with known causes of } \\
\text { chronic liver diseases. Mean }\end{array}$ & $\begin{array}{l}\text { Ultrasonography; } \\
24.3 \%(n=5,213) \text { had } \\
\text { NAFLD }\end{array}$ & $\begin{array}{l}{ }^{14} \mathrm{C} \text { urea breath test; } 10,848 \\
(50.5 \%) \text { positive cases }\end{array}$ & $\begin{array}{l}\text { Age, sex, BMI, blood } \\
\text { pressure, fasting glucose, } \\
\text { hemoglobin A1c, } \\
\text { complete lipid profile, uric } \\
\text { acid, creatinine levels }\end{array}$ & $\begin{array}{l}\text { H. pylori infection was not } \\
\text { associated with NAFLD } \\
\text { (adjusted OR } 1.0,95 \% \mathrm{Cl} \\
0.70-1.30 \text { ) }\end{array}$ \\
\hline
\end{tabular}


Yu Y et al. 2018 (21) Cross-sectional study: 20,389

(11,969 men) Chinese adult individuals after excluding

those with known causes of

chronic liver diseases. Mea age 48.3 years, mean BMl $23.7 \mathrm{~kg} / \mathrm{m}^{2}$
Ultrasonography; $\quad{ }^{13} \mathrm{C}$ urea breath test; 7,848

$37.2 \%(n=7,592)$ had

(38.5\%) positive cases
Age, sex, BMI, smoking, white blood cell count, plasma hs-CRP, fasting glucose, triglyceride, GGT levels
$H$ pylori infection was

significantly associated with NAFLD (adjusted OR 1.14,

$95 \% \mathrm{Cl} 1.04-1.38)$

\section{Longitudinal studies}

$(n=2)$

\section{Abdel-Razik et al.} 2018 (23)

Retrospective longitudinal cohort study: $17,028(8,787$ men) asymptomatic South Korean adult individuals without NAFLD at baseline, who were followed for a median period of 5.1 years (IQR 2.8-7.2 years). Mean age 49.3 years, mean BMI 23

$\mathrm{kg} / \mathrm{m}^{2}$

Multicenter pilot longitudinal study: 369 (199 men) Egyptian adult individuals without

Hepatic steatosis index

Ultrasonography; 3,381 individuals developed incident NAFLD on ultrasound over follow-

Antibodies (IgG enzyme-linked immunosorbent assay); 9,918 (58.2\%) seropositive cases

\section{Faecal antigen test; 17 \\ $(46.3 \%)$ positive cases}

NAFLD at baseline, who were followed for 2 years. Mean age 49.5 years, mean BMI 23 liver fat score (NAFLD-

LFS) > - $0.64 ; 23$

individuals developed incident NAFLD over 2$\mathrm{kg} / \mathrm{m}^{2}$. After a 24-month follow- year follow-up up, all subjects with $H$. pylori infection were treated with eradication therapy for 2 weeks and then followed up for 3 months
Age, sex, BMI, smoking status, alcohol

consumption, physical activity, education level, year of exam, blood pressure, fasting glucose complete lipid profile AST, ALT, GGT, hs-CRP, HOMA-insulin resistance, use of medications for hypertension,

dyslipidemia and diabetes Age, sex, BMI, smoking status, socio-economic status, physical activity, education level, fasting glucose, complete lipid profile, uric acid, hs-CRP, HOMA-insulin resistance
H. pylori infection was significantly associated with increased risk of developing incident NAFLD (adjusted HR 1.11, 95\% Cl 1.04-1.30). After eradication therapy for $H$. pylori infection, there were significant reductions in $\mathrm{HSI}$ (or NAFLD-LFS), HOMA insulin resistance, lipid profile, inflammatory
$H$. pylori infection was

significantly associated with increased risk of developing incident NAFLD (adjusted HR 1.16, 95\%Cl 1.05-1.30)

Abbreviations: ALT, alanine aminotransferase; AST, aspartate aminotransferase; BMl, body mass index; Cl, confidence interval; hs-CRP, high sensitivity C-reactive protein; GGT, gamma-glutamyltransferase; HOMA, homeostasis model assessment; HR, hazard ratio; HSI, hepatic steatosis index; NAFLD-LFS, NAFLD liver fat score; $\mathrm{NASH}$, nonalcoholic steatohepatitis; OR, odds ratio. 
Table 2. Subgroup analyses - Association between $H$. pylori infection and risk of prevalent NAFLD in the eligible cross-sectional or case-control studies ( $n=11$ studies, involving a total of 63,765 middle-aged individuals) stratified by levels of Newcastle-Ottawa quality assessment scale (NOS), degree of covariate adjustment, methods used for diagnosing either $\mathrm{H}$. pylori infection or NAFLD, and study country.

\begin{tabular}{|c|c|}
\hline & Newcastle-Ottawa quality assessment scale level \\
\hline NOS $\geq 8$ stars & $\begin{array}{l}\text { Random-effects OR } 1.14(95 \% \mathrm{Cl} 1.02-1.27), I^{2}=16.4 \% \\
\text { Number of studies: } 6 \\
N=51,563\end{array}$ \\
\hline \multirow[t]{2}{*}{ NOS $<8$ stars } & $\begin{array}{l}\text { Random-effects OR } 1.38(95 \% \mathrm{Cl} 1.09-1.73), I^{2}=74.7 \% \\
\text { Number of studies: } 5 \\
N=12,202\end{array}$ \\
\hline & Degree of covariate adjustment \\
\hline Full covariate adjustment* & $\begin{array}{l}\text { Random-effects OR } 1.19(95 \% \mathrm{Cl} 1.07-1.32), I^{2}=0 \% \\
\text { Number of studies: } 3 \\
N=28,056\end{array}$ \\
\hline \multirow[t]{2}{*}{ No full covariate adjustment } & $\begin{array}{l}\text { Random-effects OR } 1.23(95 \% \mathrm{Cl} 1.03-1.47), l^{2}=68.9 \% \\
\text { Number of studies: } 8 \\
N=35.709\end{array}$ \\
\hline & Diagnostic methods of $H$. pylori infection \\
\hline Serological test & $\begin{array}{l}\text { Random-effects OR } 1.26(95 \% \mathrm{Cl} 1.0-1.61), I^{2}=56.0 \% \\
\text { Number of studies: } 4 \\
N=10,876\end{array}$ \\
\hline \multirow[t]{2}{*}{ Urea breath test } & $\begin{array}{l}\text { Random-effects OR } 1.19(95 \% \mathrm{Cl} 1.02-1.39), l^{2}=66.4 \% \\
\text { Number of studies: } 7 \\
N=52,889\end{array}$ \\
\hline & Diagnostic methods of NAFLD \\
\hline Biopsy & $\begin{array}{l}\text { Random-effects OR } 3.15(95 \% \mathrm{Cl} 1.47-6.75), I^{2}=0 \% \\
\text { Number of studies: } 2 \\
N=183\end{array}$ \\
\hline Ultrasonography & $\begin{array}{l}\text { Random-effects OR } 1.18(95 \% \mathrm{Cl} 1.04-1.34), I^{2}=60.8 \% \\
\text { Number of studies: } 8 \\
N=59,919\end{array}$ \\
\hline \multirow[t]{2}{*}{ Hepatic steatosis index } & $\begin{array}{l}\text { Random-effects OR } 1.13(95 \% \mathrm{Cl} 0.97-1.31) \\
\text { Number of studies: } 1 \\
N=3,663\end{array}$ \\
\hline & Study country \\
\hline Greece & $\begin{array}{l}\text { Random-effects OR } 3.61(95 \% \mathrm{Cl} 1.04-12.57) \\
\text { Number of studies: } 1 \\
N=53\end{array}$ \\
\hline Asia & $\begin{array}{l}\text { Random-effect OR } 1.19(95 \% \mathrm{Cl} 1.05-1.35), I^{2}=62.8 \% \\
\text { Number of studies: } 9 \\
N=58,308\end{array}$ \\
\hline United States & $\begin{array}{l}\text { Random-effects OR } 1.17(95 \% \mathrm{Cl} 0.95-1.44) \\
\text { Number of studies: } 1 \\
N=5,404\end{array}$ \\
\hline
\end{tabular}

*Full covariate adjustment was arbitrarily defined as studies adjusting at least for age, sex, BMI, smoking history, diabetes and other common metabolic risk factors. 